\title{
El voto femenino en El Puerto en La Segunda República
}

ISABEL PÉREZ SÁNCHEZ

El período de la II República, en el que se va a centrar este tema del voto femenino, ha constituído para muchos historiadores, tanto españoles como foráneos, objeto fundamental de investigación. Pero, a pesar de existir una amplia y variada bibliografía sobre el mismo, son todavía muy pocas las investigaciones que se centran en el estudio de las mujeres en dicho período histórico. Por esta razón, es necesario reconstruir la historia de la II República, integrando en ella a las mujeres, constatando su presencia y participación, en esta época en la que su actuación política fue particularmente privilegiada ${ }^{1}$ si se compara con períodos históricos anteriores en los que la marginación de las mujeres en el terreno político era, se puede decir, casi total.

A pesar de que en la escena política española la concesión del voto a las mujeres había sido tratada en varias ocasiones, fue en la II República cuando éstas adquirieron tal derecho sin limitaciones. Ello suscitó las más enconadas oposiciones y las opiniones más diversas. Miedos y entusiasmos se enfrentaron ante la realidad de que más de la mitad del electorado lo íba a constituir mujeres, de las que se decía dependería el futuro de la propia República.

El tema del voto femenino despierta de por sí interés a los estudiosos de la Historia de las Mujeres, por lo que supuso de avance y conquista en su participación política, pero aún es más interesante por los tópicos que se le han ido atribuyendo repetidamente, como la victoria de la derecha en las elecciones de 1.933 y el triunfo del Frente Popular en 1.936. Estos supuestos, insuficientemente investigados en la mayoría de los casos, han simplificado unos hechos históricos sumamente complejos, desvirtuándose así la realidad histórica. Es preciso, por tanto, llevar a cabo investigaciones que vayan esclareciendo y completando el sufragio

(1) NASH, MARY: Mujer y movimiento obrero en Eqaña, 1931- 1939. Barcelona, 1981. Pág. 17. 
femenino, y, sobre todo, realizar estudios que no traten el tema limitándose sólo a su posible influencia en los resultados electorales, sino que tengan en cuenta otros aspectos sin los cuales no se podría entender el voto femenino.

Así pues, para comprender el tema en toda su complejidad, habría que profundizar en las siguientes cuestiones:

- La situación social de las mujeres cuando se les concede el voto. Su nivel cultural, su incorporación laboral y participación política. Su actitud ante tal concesión.

- La importancia de este derecho político para las mujeres de esa época y si incidió de alguna manera en la concepción que de ellas se tenía y en sus realidades.

- El significado del voto para las mujeres según su situación económica y cultural, ya que éstas no constituyen un todo abstracto, sino que aunque se diferencian de la otra mitad de la población por su sexo/ género, también se diferencian entre sípor el lugar que ocupan en las relaciones de producción, es decir, por la clase social a la que pertenecen ${ }^{2}$.

- El tipo de campaña electoral que se realiza con las mujeres desde los diferentes partidos, pues se refleja la concepción que se tenía de ellas y también los verdaderos intereses de muchos de los 'grupos políticos que participaban en la contienda electoral.

- El estudio del voto, no como algo aislado dentro del ámbito político, sino como un hecho que se da en un período que viene acompañado de otras mejoras que van a incidir claramente en la vida de las mujeres.

Desde éstas y otras perspectivas se ha pretendido abordar el voto femenino en El Puerto de Santa María. El plantear estas cuestiones en esta ciudad, no ha estado exento de grandes dificultades. Querer tratar el tema del sufragio en un ámbito tan reducido y local, y la falta, en muchos casos, de la documentación necesaria, han condicionado los resultados. Esto ha podido ser resuelto, en gran parte, ya que en todo momento se ha ido contrastando y relacionando la situación local con la general en el país y llevando a cabo, en la medida de lo posible, entrevistas con personas que vivieron estos acontecimientos ${ }^{3}$.

(2) FAGOAGA, CONCHA: La voz y el voto de las mujeres. 1877-1931. Barcelona, 1985. Pág. 9.

(3) La utilización de la Historia Oral llena y suple muchos vacios históricos documentales y es de gran ayuda para los historiadores de la Historia de las Mujeres. Puede consultarse: ALINE BARRACHINA, MARIE, -Ventajas y problemas que ofrece la entrevista para el estudio del periodo de la II República. y FOLGUERA, PILAR, la historia oral como fuente para el estudio de la vida cotidiana de las mujeres. en La mujer en la Historia de España (siglos $X V I-X X$ ). Actas de las segundas jornadas de investigación interdisciplinaria. Madrid, Universidad Autónoma, 1984. También los trabajos de M. VILANOVA, C. BORDERIAS, etc. en la revista HISTORLA Y FUENTE ORAL, Núm. 6 Otras Miradas. Barcelona, 1991. 
La consecución del voto femenino en España fue muy diferente a las de otros países como EE.UU. y Gran Bretaña ${ }^{4}$. En ellos el desarrollo industrial y el consiguiente poder de las clases medias y los núcleos liberales favorecieron la consolidación de un movimiento feminista ${ }^{5}$. En España, nuestro feminismo fue escaso y tardío $0^{6}$; incluso se puede decir que nunca llegó a formar lo que se llama movimiento, ni se puede hablar con propiedad de organizaciones feministas. El feminismo español se vería envuelto en el conflicto ideológico de la izquierda y la derecha y no tendría un desarrollo independiente como movimiento específico ${ }^{7}$. A pesar de ello, sí hubo grupos reducidos que, por sus ideas y objetivos, participaron de la gran corriente del movimiento feminista ${ }^{8}$. De este modo, por canales muy minoritarios, se fueron planteando temas básicos como el acceso a la educación, reforma moral, derechos económicos y sufragio". Al instaurarse la II República es cuando se van a pretender llevar a cabo todos estos temas pendientes ${ }^{10}$.

Con el sufragismo ${ }^{11}$ se planteaba una visión de la realidad en la que las mujeres debían participar directamente en la vida pública en igualdad con los hombres ${ }^{12}$. Este planteamiento chocaba con el papel social que tenían impuesto, donde la participación política no tenía cabida.

El sufragio femenino, que se había convertido en símbolo del movimiento feminista durante el primer cuarto del siglo XX, se va a plantear

(4) Véase: EVANS, RICHARD J, las Feministas. Los movimientos de emancipación de la mujer en Europa; América y Austrasia, 1840-1920. Madrid, 1980 y LLOYD, TREVOD, Las Sufragistas. Barcelona, 1970.

(5) GONZALEZ CASTILLEJO, M JOSE: La nueva bistoria. Mujer, vida cotidiana y esfera pública en Málaga (1931-1936). Málaga, Universidad, 1991. Pág. 259.

(6) CAPEL MARTINEZ, ROSA: -El sufragio femenino en la Segunda República Española. en Anuario de Historia Moderna y Contemporánea. Tomos II y III. Universidad de Granada, 1975/76. Pág. 200.

(7) MORCILLO GOMEZ, AURORA: -Feminismo y lucha política durante la II República y la Guerra Civil. en El Feminismo en España: Dos siglos de bistoria. Madrid, 1988. Pág. 58.

(8) DOMENECH, ASUNCION: -El voto femenino. en Cuadernos. Historia 16, Núm. 163. Pág. 20.

(9) IBIDEM. Pág. 22.

(10) Las mujeres participaron ampliamente del ambiente de júbilo y fiesta que produjo la liegada de la II República, sin duda esperanzadas por las espectativas que podían traerles en su situación, incluso se llamó a la República la eniña bonita. pues fue con ella cuando las mujeres comenzaron a salir políticamente y en forma masiva a la calle. JULIA, SANTOS: -La última revolución popular. en La Guerra Civil. Historia 16, Núm. 1. Madrid, 1986. Pág. 68.

(11) Se puede afirmar que sufragismo y feminismo son dos términos que se identificaron en un determinado momento de la Historia de las Mujeres. MORCILLO GOMEZ, AURORA, op. cit. Pág. 70 .

(12) FAGOAGA, CONCHA, op. cit. Pág. 18. 
en España con unas connotaciones muy determinadas, debido a las condiciones de nuestro pais, que impedían el surgimiento de este movimiento feminista: débil industrialización, clase media insuficiente que aporte mujeres necesitadas de trabajo, escasa formación intelectual femenina y ausencia de un sistema democrático de gobierno ${ }^{13}$. Y al mismo tiempo, por la existencia de una rígida distribución de los papeles sociales: las mujeres tenían asignado el cuídado del hogar y la familia(la llamada esfera privada), mientras que los hombres tenían acceso a la esfera pública, es decir, el ámbito laboral y sindical, la cultura, estudios profesionales, la política...

Desde principios de nuestro siglo esta situación se va a ir modificando paulatinamente con la incorporación progresiva de las mujeres a parcelas de esta esfera pública. Las mujeres van accediendo al proceso de producción industrial, aunque este acceso al trabajo estará condicionado por determinadas circunstancias ${ }^{14}$. Y en cuanto al aspecto cultural, aunque en el primer tercio del siglo XX la enseñanza de la mujer fue objeto de un relativo impulso, tanto oficial como privado, en vísperas de la proclamación de la II República, la mayoría de la población femenina se mantenía en niveles muy altos de analfabetismo, y sólo un grupo minoritario adquiría una formación intelectual avanzada ${ }^{15}$. Este grupo de mujeres va a ser el que introduzca en España las ideas feministas (las afiliadas al tLiceum Club", la *Asociación de Mujeres Españolas"...), y va a luchar por conseguir la igualdad con el hombre en el disfrute de las leyes (igualdad legal), derecho al sufragio, igualdad cultural, laboral... Pero la mayoría de la población femenina, las mujeres del pueblo, no entendían la lucha feminista, e incluso, en la mayoría de los casos no conocían ni su existencia.

En El Puerto, las mujeres, según los testimonios que hemos podido recoger, estaban muy ajenas a los planteamientos feministas y, por consiguiente, a la lucha por el voto femenino. La participación política era algo muy alejado de sus deberes habituales y de la mentalidad social tradicional que existía: estaba mal visto que las mujeres participasen en la política y ésta era considerada "cosa de hombres ${ }^{16}$. Las funciones principales de las mujeres portuenses, seguían siendo el cuídado del hogar y la familia, manteniéndose la concepción ya comentada sobre la división de papeles entre mujeres y hombres.

(13) CAPEL MARTINEZ, ROSA, op. cit. Pág. 199.

(14) Pueden consultarse: NUÑEZ PEREZ, Mª GLORIA, Trabajadoras en la II República. Madrid, 1989; CAPEL MARTINEZ, ROSA, El trabajo y la educación en España (1900 1930). Madrid, 1986; NASH, MARY, Mujer, Familia y Trabajo en España, 1875-1936. Barcelona, 1983.

(15) CAPEL MARTINEZ, ROSA, op. cit. Pág. 200.

(16) Testimonio oral de M.D.A., el 24 de enero de 1991. 
Esta situación se verá claramente reflejada al estudiar el Padrón de Habitantes de 1930. A partir de él se van a analizar dos indicativos fundamentales: la incorporación laboral femenina y su nivel de instrucción y analfabetización. Con ello se puede llegar a conocer cuál era la situación de las mujeres portuenses antes de que se les concediese el yoto $\mathrm{y}$, además, se consigue un acercamiento sobre cuáles eran las características del electorado femenino, que iba a hacer uso del sufragio por vez primera en las elecciones del 19 de Noviembre de 1933.

El Padrón de 1930 recoge 19.714 habitantes y está dividido en 4 Distritos y 10 Secciones. De ellos han sido estudiados 3 Distritos y 8 Secciones, alcanzándose 14.746 habitantes, lo que supone el 74,80\%17.

CUADRO I

\begin{tabular}{ccccc}
\multicolumn{5}{c}{ POBLACION PORTUENSE POR SEXOS } \\
DISTRITO & HOMBRES & $\%$ & MUJERES & $\%$ \\
1 & 679 & 45 & 841 & 55 \\
2 & 3726 & 49 & 3846 & 51 \\
3 & 2631 & 47 & 2973 & 53 \\
TOTA_LES & 7036 & 47 & 7710 & 53
\end{tabular}

FUENTA: Elaboración propia a partir del Padrón de Habitantes de 1930.

Como se puede observar el porcentaje de mujeres censadas es superior al de los hómbres. En España la media de mujeres para este mismo año es del $51 \%$. En El Puerto supera este porcentaje en dos puntos, alcanzando el $53 \%$ frente al $47 \%$ de hombres.

\begin{tabular}{lcccc} 
& \multicolumn{5}{c}{ CUADRO II } \\
& POBLACION ACTIVA PORTUENSE \\
& \% SOBRE LA & \% SOBRE LA & \% SOBRE LA POBL. \\
HOMBRES & 4490 & POBL. TOTAL & POBL. ACTIVA & TOTAL DE CADA SEXO \\
MUJERES & 383 & 41 & 92 & 88 \\
TOTALES & 4873 & 4 & 8 & 7 \\
\hline
\end{tabular}

FUENTES: Elaboración propia a partir del Padrón de Habitantes de 1930. Los datos han sido obtenidos de los tres Distritos estudiados y se ha tomado la edad de 12 años como la mínima, ya que la incorporación al trabajo era muy temprana.

La población activa femenina, como queda reflejado en el Cuadro II, era muy baja, tanto si se compara con la población total de su sexo (5761

(17) Este Padrón se encuentra en el Archivo Municipal de El Puerto de Santa María (en adelante A.M.E.P.S.M.). A pesar de no haberse estudiado la totalidad de Padrón, el porcentaje es lo bastante considerable como para obtener unos resultados fiables. 
mujeres), representando un 7\%, como con la población activa total -4873llegando sólo al $8 \%$. Estos porcentajes confirman que eran los hombres los que participaban mayoritariamente en el ámbito laboral, y la marginación y la escasa integración de las mujeres en este campo.

Por sectores económicos, es el terciario el que alcanza el porcentaje más alto en la población activa femenina con el $87 \%$ con respecto a los otros sectores. Esto es debido a que es en este sector donde se concentran las profesiones de las mujeres. En El Puerto, el Servicio Doméstico y los diferentes grupos de religiosas (el llamado Culto y Clero) centralizan la mayor parte de la dedicación femenina.

\begin{tabular}{lcc}
\multicolumn{3}{c}{ CUADRO III } \\
\multicolumn{3}{c}{ POBLACION ACTIVA FEMENINA POR SECTORES ECONOMICOS } \\
SECTORES & POBL. FEMENINA ACTIVA & \% POR SECTORES \\
PRIMARIO & 10 & 3 \\
SECUNDARIO & 39 & 10 \\
TERCIARIO & 334 & 87
\end{tabular}

FUENTE: Elaboración propia a partir del Padrón de Habitantes de 1930. Los datos aportados se basan en los tres Distritos estudiados y se ha tomado la edad de 12 años como la mínima.

De las 5.761 mujeres que constituyen la población total femenina (mayor de 12 años), 5.237 aparecían en el Padrón con el denominativo profesional de ssu casa", es decir, el 90,90\%. Este porcentaje es aún más alto en los resultados obtenidos con la población femenina y masculina de 18 y 21 años en adelante, llegándose al 91,77\% y al 92,69 \% respectivamente ${ }^{18}$. Estos elevados porcentajes confirman la escasa incorporación de las mujeres al ámbito laboral, así como la fuerte división de los roles tradicionales en la sociedad portuense.

A pesar de todo ello, se deben tomar los datos del Padrón con ciertas reservas, ya que muchas veces no quedan registrados muchos de los trabajos realizados fuera del hogar, al ser, en la mayoría de los casos, temporales, razón por la cual no se declaraban ${ }^{19}$.

Sabemos por otras fuentes (Documentales, Orales, Material Fotográfico, Panfletos, "Bases de Trabajo", etc,), que en algunas ocupaciones de los distintos sectores económicos las mujeres tenían una amplia participa-

(18) Estos porcentajes han sido obtenidos a partir de los datos del Padrón de 1930. Se ha querido, con estas edades, aproximarse a las mujeres que estarían comprendidas en el Censo Electoral. A.M.E.P.S.M., Leg. H-548. Edicto de Francisco Cossi Ochoa .Instrucción para llevar a efecto la formación del censo electoral.

(19) SOTO CARMONA, ALVARO: .Cuantificación de la mano de obra femenina (1860-1930). en La mujer en la Historia de España (siglos XVI-XX). Actas de las II Jornadas de Investigación Interdisciplinaria. Madrid, Universidad Autónoma, 1984. Pág. 280. 
ción que no ha quedado, sin embargo, recogida en el Padrón. En el sector primario, las mujeres trabajaban en tareas de preparación del campo y en épocas de recolección y vendimia. En el Sector Secundario, tanto en las Bodegas como en la fábrica de Conservas 'SUR ${ }^{20}$, está verificada la presencia femenina. También en el Sector Terciario se ha podido constatar, por testimonios orales, que el número de empleadas domésticas era muy superior al que aparece en el Padrón, dado que muchas mujeres realizaban el servicio doméstico por horas o tareas eventuales a domicilio y no se declaraban como activas en este sector ${ }^{21}$.

El nivel de instrucción de las mujeres también es significativo de la situación en que vivían. En general tenían un nivel de escolarización menor al de los hombres y la enseñanza que recibían estaba claramente influenciada por los conceptos tradicionales sobre las funciones que debía desempeñar a lo largo de su vida (casa, marido, hijos).

Siguiendo con el Padrón de 1.930, han quedado registrados como escolares o colegiales 277 (estos datos han sido tomados de la población de 12 años en adelante), de los cuales el 56\% son hombres, y el $45 \%$ mujeres. Esta diferencia de porcentaje es mayor en los casos en que se denominan estudiantes. Así, aparecen 79 hombres y 15 mujeres, con unos porcentajes respectivos del $84 \%$ y $16 \%$. Esta desigualdad se hace extrema en los estudiantes mayores de 18 años. Para los Distritos 1 y 2 han quedado inscritos 49 hombres y sólo 3 mujeres, es decir el $94 \%$ y el $6 \%$, respectivamente.

Todos estos datos demuestran que, aunque en los niveles primarios de la enseñanza no hay grandes diferencias en los porcentajes entre la población masculina y femenina, estas diferencias aumentan con la edad, y así, quienes acceden a la enseñanza media y superior son, casi en su totalidad, hombres. Por ello, a la determinante situación socio-económica de las familias, de la cual dependía el que los hijos pudieran estudiar, se añade el factor sexo como discriminador para las mujeres a la hora de recibir una educación más amplia.

Esta situación queda reflejada igualmente en el nivel de analfabetismo femenino. Las cifras de las analfabetas superan en todas las secciones estudiadas del Padrón a las de los analfabetos.

(20) PEREZ SANCHEZ, ISABEL: -Las obreras conserveras portuenses durante la II República. en La mujer en la provincia de Cádiz a través de la bistoria. II coloquio de Historias Locales de Cádiz. Cádiz, Diputación Provincial, 27-28 octubre 1990. En prensa.

(21) NUÑEZ PEREZ, P1ª GLORIA, op. cit. Pág. 112. 


\section{CUADRO IV}

TASAS Y PORCENTAJES DEL ANALFABETISMO PORTUENSE

\begin{tabular}{lccccc} 
& \multicolumn{3}{c}{ ALFABETIZADOS } & \multicolumn{2}{c}{ ANALFABETOS } \\
& Totales & Número & $\%$ & Número & $\%$ \\
DISTRITO 1 & & & & & \\
HOMBRES & 515 & 381 & 74 & 134 & 26 \\
MUJERES & 690 & 444 & 64 & 246 & 36 \\
DISTRITO 2 & & & & & \\
HOMBRES & 2828 & 1861 & 66 & 967 & 34 \\
MUJERES & 3046 & 1749 & 59 & 1297 & 43 \\
DISTRITO 3 & & & & & \\
HOMBRES & 2046 & 1465 & 72 & 581 & 28 \\
MUJERES & 2380 & 1526 & 64 & 854 & 36
\end{tabular}

FUENTE: Elaboración propia a partir del Padrón de Habitantes de 1.930. Se han considerado analfabetos las personas de 10 y más años de edad que no saben leer ni escribir, siguiendo el criterio metodológico adoptado por el Instituto Nacional de Estadística a partir de 1.950 .

Los porcentajes son lo suficientemente demostrativos como para poder afirmar que el analfabetismo, debido a múltiples causas, es un fenómeno que incide más directamente en las mujeres que en los hombres $^{22}$. Los resultados obtenidos con la población femenina de 18 y 21 años en adelante, no varían considerablemente de los expuestos en el Cuadro IV, por lo que no es necesaria su alusión. Los datos reflejados en dicho Cuadro para los tres distritos ocultan el que hubiesen diferencias muy importantes, dentro de las secciones estudiadas, en relación a la población analfabeta portuense. Por ejemplo, en las Secciones 2.2 y 2.3 del Distrito 2, el porcentaje de analfabetismo femenino aumenta hasta el $65 \%$ y $53 \%$, respectivamente, mientras que, en esa mismo Distrito, en la Sección 2.5 , se rebaja al $28 \%$ el nivel de analfabetas.

Estas diferencias se pueden llegar a relacinar con la situación socioprofesional, e incluso, con la localización de estas secciones. Esta última sección (2.5) se encuentra en la zona céntrica de la ciudad y en las profesiones de los hombres existe un alto porcentaje de comerciantes, empleados, profesiones liberales..., mientras en los casos anteriores (2.2 y 2.3), el trabajo mayoritario es el del campo y habitan en la * zona alta* de la ciudad. La posición económica es un elemento determinante para poder adquirir unos niveles culturales.

(22) VILANOVA, MERCEDES y MORENO, XAVIER: •Analfabetismo y censos de población en España de 1887 a 1981. en Historia y Fuente Oral. Núm. 7 .Analfabetismo y Política. Barcelona, 1992. Pág. 164. También puede consultarse, por los mismos autores: Atlas de la exolución del analfabetismo en España de 1887 a 1981. Madrid, Ministerio de Educación y Ciencia y C.I.D.E., 1992. 
A nivel general se puede observar que la situación de las mujeres de El Puerto es similar a la mayoría de la población femenina española: falta de preparación cultural, escasa integración en el campo laboral y participación en la política prácticamente nula.

Estas condiciones no propiciaban que las españolas luchasen por conseguir el derecho al voto y otros derechos que ya poseían las mujeres en otros países, resultando, como ya se ha dicho, un movimiento feminista minoritario. Sólo un grupo de mujeres se planteaba y luchaba por conseguir el sufragio femenino. Pero éste no se alcanzará por la lucha decidida de las mujeres, sino que va a ser en el parlamento donde algunos políticos llevados por sus propios ideales conseguirán el derecho al voto.23.

\section{2}

Después del 14 de Abril de 1931 en que queda instaurada en España la II República, el gobierno provisional convoca elecciones a Diputados para el 28 de Junio de 1931, concediéndole a las mujeres el Derecho Pasivo, es decir, la posibilidad de ser elegidas, pero sin poder votar. De los 470 diputados elegidos, 3 eran mujeres: Clara Campoamor, Victoria Kent y Margarita Nelken. El 14 de Julio se inaguraban las Cortes; tenían que elaborar la Constitución, y entre otros temas debían tratar el sufragio femenino. Tras una fuerte polémica fue aprobado por 160 votos a favor y 121 en contra. No obstante, se propusieron unas enmiendas que cuestionaban el anterior resultado, votándose definitivamente el 1 de Diciembre y resultando 131 votos a favor por 127 en contra. Como se puede observar, el estrecho margen del resultado prueba lo reñido y contradictorio de la votación y el serio peligro que corrió de no ser aprobado. Por sólo cuatro votos de diferencia las mujeres españolas seguirían manteniendo su derecho al sufragio.

Muchos fueron los argumentos manejados en contra del voto femenino: incapacidad natural de la mujer, escasa cultura, confesionalismo, inexperiencia política, etc... La derecha, desde un principio, apoyó la concesión del voto femenino, ya que veráuna oportunidad para inclinar la balanza política hacia sus formaciones, basándose en la influencia que sobre la mujer ejercía la iglesia. Los grupos liberales y de izquierda estaban muy desunidos. Ideológicamente, negar el voto a las mujeres era algo inadmisible y contradictorio en un estado liberal-democrático. Los socialistas, aunque con deserciones, consecuentes con su programa ideológico, estaban por tal concesión. En cambio, los radicales, radicales socialistas y Acción Republicana la consideraban inoportuna.

(23) FAGOAGA, CONCHA y SAAVEDRA, PALOMA: Clara Campoamor. La sufragista española. Madrid, 1986 ( $2^{\mathbf{z}}$ ed.). Pág. 13. 
Dos mujeres protagonizaron el intenso debate. Victoria Kent, acatando la disciplina de su partido, propuso el aplazamiento de la concesión del voto ${ }^{24}$, alegando que las mujeres aún no estaban preparadas; había que instruirlas y concienciarlas previamente a fin de que no pusieran en peligro la República. Clara Campoamor, con argumentos profundamente feministas, mantuvo por encima de los intereses políticos el principio de igualdad en primer plano frente a las consideraciones utilitarístas que exponía Kent.

A Clara Campoamor se le puede considerar como la única sufragista española. Llevó el peso de los debates casi en solitario, con la oposición de su propio partido y de la mayor parte de los republicanos. En esta batalla dialéctica fue la vencedora. Los ideales se impusieron definitivamente a la oportunidad política y a las consideraciones de tipo práctico ${ }^{25}$. El artículo 36 de la Constitución quedaría: ‘Los ciudadanos de uno y otro sexo, mayores de 23 años, tendrán los mismos derechos electorales conforme determinen las leyes ${ }^{26}$. Sim embargo, su postura le conduciría a una muerte súbita en la política y, más aún, después de los resultados electorales ${ }^{27}$.

En este momento cabe preguntarse cuál seria la actitud de las mujeres de El Puerto ante la concesión del voto.

En El Puerto la concesión o no del voto femenino no tuvo eco local según la documentación consultada. No hay en estos meses, desde Septiembre a Diciembre de 1931, referencias en la prensa sobre la polémica en torno al sufragio femenino en España (se ha consultado diariamente, entre otros, el periódico local la Revista Portuense:).

Se puede decir que en El Puerto la mayoría de las mujeres permanecían ajenas al hecho de que estaban a punto de conseguir el derecho al voto. Sus intereses cotidianos posiblemente estaban muy alejados de un planteamieto sobre su participación o no política y, de hecho, en estos primeros meses de la II República las discusiones parlamentarias sobre la concesión o no del voto ocurrían en escenarios remotos, muy alejados de sus verdaderos problemas. Como nos dice $\mathrm{M}^{2}$ Dolores Ramos: "Una obra representada entre bastidores por y para la burguesía, de espaldas a esa realidad cotidiana de explotación, supervivencia

(24) En el Diario de Cádiz se ha encontrado, en la sección -Información Telefónica., las discusiones parlamentarias en torno al voto de la mujer. 1-3 octubre 1931.

(25) CAPEL MARTINEZ, ROSA, op. cit. Pág. 239.

(26) GARCIA MENDEZ, ESPERANZA: La actuación de la mujer en las Cortes de la II Repüblica. Madrid, 1979 ( $2^{2}$ ed.). CAPEL MARTINEZ, ROSA, op. cit. Pág. 226.

(27) CAMPOAMOR, CLARA: Mi pecado mortal. El voto femenino y yo. Introducción de Concha fagoaga y Paloma Saavedra. Barcelona, 1981. 
y lucha por la vida en que transcurría la existencia de tantas familias y mujeres españolas. ${ }^{28}$.

Podrían establecerse tres grupos que representarían más o menos las posturas de las mujeres portuenses ante la concesión del sufragio: La mayoría de las portuenses, a finales de 1.931, podrían incluirse en el grupo de mujeres españolas para las que lo más importante era sacar su casa adelante. Para ellas; carecen de significado los conceptos de derechos femeninos y de sufragio. Viven inmersas en su realidad. (muy diferente a la de las sufragistas -mujeres de élite cultural y económica-), son en su mayoría analfabetas y sin más horizonte que su hogar ${ }^{29}$. En general supieron que podían votar en la campaña electoral que se produjo antes de las elecciones de 1933.

Pero también hubo en El Puerto algunas mujeres que fueron más conscientes del significado del derecho al voto. Eran mujeres que se encontraban más cercanas a la política porque su marido o algún familiar militaba en partidos políticos y estaban influídas por las ideologías de ellos. Estas mujeres valoraban la República y los avances logrados. Eran las que estaban más relacionadas con la izquierda y entre las que se encontraban algunas de las obreras más conscientes ${ }^{30}$.

Por último, no podemos olvidar al grupo de mujeres que pertenecían a la clase alta y parte de la clase media portuense y que estaban organizadas o relacionadas con asociaciones religiosas, sobre todo :ACción Católica", guardando relación con los grupos políticos conservadores y de derechas. Estas mujeres que estaban muy organizadas en la II República, protagonizaron una recogida de firmas a finales de Mayo y Junio de 1931, para protestar por las medidas anticlericales del gobierno ${ }^{31}$. Para ellas, siguiendo la ideología de la derecha, el voto femenino iba a ser una forma de conseguir el poder y que España no siguiera por el -camino descarriado* que era la República. Van a trabajar especialmente antes de las elecciones con el fin de obtener para los partidos de derechas el voto femenino.

(28) RAMOS PALOMO, DOLORES: -Luces y sombras en torno a una polémica: La concesión del voto femenino en Esspaña (1931-1933). en BAETICA, núm. 11. Málaga, Universidad, 1988. Pág. 565.

(29) Al estudiar el Padrón de 1930, se ha podido comprobar la existencia de un gran número de mujeres dedicadas a su casa, o con unos trabajos temporales con los que poder ayudar a la economía familiar.

(30) Consideraciones aportadas a partir de diversos testimonios orales.

(31) REVISTA PORTUENSE, 30 de mayo de 1931: .Las damas católicas del Puerto de Santa María en número de más de dos mil elevan un telegrama al Jefe de Gobierno por la defensa de la causa católica en España. 
Según la postura de las mujeres de El Puerto y de la mayoría de la población femenina española con respecto al voto, podemos decir que, en general, a las mujeres se les concedió el voto:

- Sin que en su mayoría lo pidiesen (sólo los grupos feministas minoritarios lucharon por su concesión -ANME, Liceum Club- además de algunos grupos parlamentarios). político).

- Sin que estuviesen preparadas para ello (por su distanciamiento

- Sin que, en líneas generales, fuesen capaces de valorar el significado de la decisión de concederles el voto.

Tres cuestiones fueron básicas e influyeron decisivamente a la hora de conceder el voto a las mujeres: la presión ideológica de los partidos de izquierda; la presión internacional que sufrían todos los partidos, ya que muchos países ya tenían el sufragio femenino y su reconocimiento se convirtióen una prueba exterior de democracia ${ }^{32}$, y la importante labor de Clara Campoamor que, como se puede comprobar en el Diario de Sesiones $^{33}$, luchócasi en solitario para que las mujeres españolas tuviesen el derecho al sufragio.

Pero a pesar de todo ello, en ese momento la concesión del voto femenino fue muy importante, no sólo por la obtención de un derecho político que igualaba a mujeres y a hombres sin tener en cuenta diferencias económicas, sociales, culturales, ni de sexo, sino porque el voto dejó una.puerta abierta* a una participación más amplia en el ámbito político. No en la consideración primera que se quiso hacer del sufragio femenino como medio de hacer llegar la voz de las mujeres a las capas oficiales y obligar a los gobernantes a ocuparse de sus problemas, sino en el hecho de que al votar se debía con anterioridad comprender las diferentes opciones y programas de los partidos, lo que forzaba a que las mujeres asistieran a actos públicos: mítines reuniones, conferencias... y se planteasen cuestiones hasta entonces poco habituales. También, por otro lado, la concesión del voto, forzaba a los partidos a preocuparse por las mujeres, a interesarse por concienciarlas políticamente afín de que les pudiesen votar. Así, este derecho podía incidir directamente en esta tradicional separación de esferas, pudiendo entrar en contradicción el alejamiento que las mujeres tenían de la política, con la necesaria participación que se les empezaba a exigir.

Sin embargo, tampoco hay que hacerse ilusiones. En contra de estas posibilidades que podía traer consigo el voto, se daban otros hechos de bastante importancia:

(32) CAPEL MARTINEZ, ROSA, op. cit. Pág. 199.

(33) GARCIA MENDEZ, ESPERANZA, op. cit. FAGOAGA, CONCHA y SAAVEDRA, PALOMA: Clara Campoamor. La sufragista española, op. cit. 
- Por parte de la sociedad en general, que era todavía reacia a la participación femenina en la política. La mentalidad no desaparece en tan poco tiempo y

- Por parte de los partidos, debido a que con la concesión del voto no se pretendió en ningún caso acabar con la rígida distribución de los roles sociales.

Esto se percibe claramente en las derechas, pues para ellos el estar a favor del sufragio femenino, no significaba que estuviesen de acuerdo con propiciar a las mujeres un derecho que las igualara al hombre, sino que se trataba de puro oportunismo político, no optando por cambiar para nada las tradicionales funciones femeninas, como así queda constatado en un artículo de la Revista Portuense, escrito después de las elecciones y en el que se dice:

"Si, vuelve, mujer al hogar donde tienes la alta misión que cumplir como madre, como esposa, como hija, como hermana y deja ya las contiendas de estos días que te alejan de ese ambiente plácido donde ejerces la soberanía con plenitudde derechos y sin las acritudesde la lucha política..., ${ }^{34}$.

Por otra parte, la izquierda (socialistas y comunistas) intentaron concienciar algo más a las mujeres de su nueva situación y sus posibilidades, pero el poco tiempo y la necesidad de conseguir sus votos, hicieron que no llevasen a cabo una verdadera labor de concienciación, ni de cambio, ni de promoción individual como mujeres, sino que al dirigirse a la población femenina también se ampararon en los conocidos valores tradicionales del esposo, hijos, hogar...

En resumen, se puede decir que el voto femenino fue importante, aunque no tendría grandes repecusiones en el incremento de la participación política femenina, y fue debido a que la sociedad seguía siendo muy tradicional con respecto a las funciones sociales de las mujeres, y a que los partidos se interesaron, sobre todo, por los votos femeninos y no por un verdadero cambio en las mujères.

3

Llegado a este punto en que se ha conseguido el voto femenino, las espectativas se centran ahora en las primeras elecciones en que participaban las mujeres, las del 19 de Noviembre de 1933.

(34) REVISTA PORTUENSE 28 de noviembre de 1933; -Retorna, mujer, a tu hogar. 
Primeramente se va a analizar la campaña electoral que se llevó a cabo en El Puerto con respecto a las mujeres desde los diferentes partidos ${ }^{35}$.

Tanto los partidos de la izquierda como los de la derecha le van a conceder una importancia notable al voto femenino, siendo para ellos determinante en los resultados electorales. Según estos partidos, quién obtuviera los votos de las mujeres ganaría las elecciones, y todos coinciden en que los votos femeninos están de su parte. En la Revista Portuense se dice: "ciego se necesita ser para no ver del lado que ha de inclinarse la mujer española, ${ }^{36}$ y también: .la mujer, por el número y calidad de su voto, tiene en sus manos los destinos de la Patria Española ${ }^{37}$, mientras en Trabajo! Organo de la Federación Portuense de Sociedades Obreras. «... la mujer de ahora no es la de antaño, la mujer sabe lo que es la República ....38. Pero en realidad, el voto femenino era una incógnita, y unos y otros iban a poner todo su empeño en conseguirlo.

La Revista Portuense comienza su propaganda de captación de las mujeres el día 18 de Octubre de 1933, prácticamente un mes antes de las elecciones ${ }^{39}$, mientras que en Trabajo! ya hay artículos que tratan el tema del voto femenino en Abril ese mismo año.

La campaña propagandítica de la izquierda se va a centrar, sobre todo, en las siguientes cuestiones:

- El importante papel que había jugado el Partido Socialista de cara a la consecución de mejoras legales para las mujeres (voto, reconocimiento personalidad jurídica,...):

.... por los votos socialistas en el Parlamento,los que han decidido que en lo sucesivo la mujer tenga iguales derechos políticos que el hombre. ${ }^{40}$.

-La importancia de la República, por las ventajas que ésta había aportado a las mujeres, por lo que debían defenderla:

-La República ha puesto en tus manos unos derechos de ciudadanía que la monarquía te negaba ... Hoy ya eres libre; ya puedes levantar tu voz; y puedes ejercer tus derechos de madre y ciudadana. ¿Quién te ha elevado a esa condición? ¡La República!‘¹.

(35) Para ello, se ha utilizado, sobre todo, dos periódicos: TRABAJO!, que era el órgano de la Agrupación Socialista y de la Federación de Sociedades Obreras, representa las opiniones de la izquierda y la REVTSTA PORTUENSE, de ideología más conservadora y donde aparece la propaganda de la derecha.

(36) REVISTA PORTUENSE. 18 de octubre de 1933, *Ante las próximas elecciones.

(37) REVISTA PORTUENSE. 7 de noviembre de 1933, El mitin de la Unión Ciudadana y Agraria.

(38) TRABAJO!. 4 de noviembre de 1933, .Clase frente a clase.

(39) dlas derechas, convencidas de contar con el apoyo femenino, no sienten esa urgencia de atraérselo. CAPEL MARTINEZ, ROSA, op. cit. Pág. 239.

(40) TRABAjO!. 1 de abril de 1933, sa mujer y la acción social.

(41) TRABAJO!. 4 de noviembre de 1933, .Mujer .... 
- La insistencia en los valores tradicionales de las mujeres, como su familia, esposo e hijos, porque, de hecho, seguían siendo sus principales problemas, y era la mejor forma de llegar a ellas:

-Tú, mujer, eres rebelde por temperamento; tú sabes más que nadie, lo que son sufrimientos y miserias, a tíes a quien antes se le parte el corazón, cuando tus hijitos te piden pan y no tienes que darle porque los capitalistas han condenado a tu esposo al paro eterno. ${ }^{42}$.

-Votar a las derechas significa votar a los verdugos de tu clase; votar a los verdugos de tu clase es como si votaras la baja de los salarios de tus padres, esposos o hermanos ${ }^{43}$.

No se habla, sin embargo, en la mayoría de los casos, de conseguir el bienestar de las mujeres, ni de llevar a cabo transformaciones radicales en sus condiciones de vida, sino que esta transformación se derivaría del cambio del sistema socio-económico (capitalismo):

.La mujer ... sabe que el día en que triunfe la clase obrera, se acabarán tantas desigualda des, tantas injusticias, tantos crimenes, tanta pobreza, .... ${ }^{44}$.

- Por otro lado,una de las cuestiones a la que, a menudo, se hace referencia en la prensa, es la de que eran conscientes de la escasa preparación cultural y política de las mujeres y de la influencia que sobre ellas ejercían la Iglesia y las organizaciones religiosas (Acción Católica), señoritas catequístas, cura..., y el gran peso que esto suponía a la hora de votar. -En los hogares más humildes ... logra introducirse la señorita con el pretexto de una misión caritativa y con astucia e hipocresía logra adueñarse de las voluntades ....45.

-Seguro que en estos momentos has de ser requerida por toda la clericalla de las damas de crucifijo al cuello, para que les des tu voto, ... desprecia cuántas ofertas te hagan ${ }^{46}$.

-Tú obrero, no debes consertir que tus hijas vayan acompañadas de sus señoritas a emitir el voto, porque querrán aprovecharse de su ignorancia para que voten a tus enemigos. Tu debes impedirlo retirándolas de las casas de servicio en vísperas de las elecciones. ${ }^{47}$.

La propaganda de la derecha se puede resumir en la defensa de la Religión, la Patria y la Familia: :Por políticas no iría la mujer a votar. Lo hace por instinto de conservación, por patriota, y defendiendo con ello la

(42) IBIDEM.

(43) TRABAJO!. 11 de noviembre de 1933, .Ciudadanas pobres.

(44) TRABAJO!. 4 de noviembre de 1933, .Clase frente a clase.

(45) TRABAJO!. 8 de abril de 1933, Ellas y Ellos.

(46) TRABAJO!. 11 de noviembre de 1933, .Mujer Proletaria.

(47) TRABAJO!. 11 de noviembre de 1933, Obrero. 
Religión, la Patria, el hogar ....48. Mantienen a ultranza los valores tradicionales sobre las mujeres: esposo, hijos, hogar..., y su participación en las elecciones tendría como objeto su defensa:

:La mujer española es de su casa, de su hogar, de sus hijos, de sus creencias, la mujer española no va a la política, sino para defender eso mismo....49.

Le quitan al acto de votar todo el significado político: $\cdot .$. no votáis por ser políticas, lo hacéis por ser madres, esposas, hijas de familia, e incluso novias, que habéis visto cómo se desgarran sentimientos, derechos e intereses legítimos de la Religión, la Patria y la Familiaso.

Otra de las cuestiones que se trata en la prensa en numerosas ocasiones, es la importancia de que voten las mujeres, haciéndoles responsables del arreglo de la situación por la que se está pasando, si ellas les votan:

-Vosotras soís la gran esperanza de la Patria en estos momentos (...). Y es necesario que lo hagaís todas (votar). Que el domingo enseñéis a los hombres cómo es de valiente la mujer española. Contra el propio miedo de muchos maridos, la mujer le enseñaráque es hora de salvarlo todo o de perderlo todo. ${ }^{51}$.

El abstencionismo femenino parece que es más temido por la derecha que por la izquierda, ya que daba por hecho que los votos de las mujeres serían para ellos. En la prensa hay varios artículos sobre los "peligros. que pueden acosar a las mujeres, tanto para que no voten: slos varones cuando os digan: en la esquina hay pelea, quédate en casa porque las mujeres no tienen que hacer nada en esas contiendas de la calle.... ${ }^{52}$, como para que voten por la candidatura de izquierda: «os dirán que fulanito o tal que es de izquierda es bueno ... ese es el peligro porque a vosotras no os combatirán de frente ${ }^{53}$. Insisten en que las mujeres voten las primeras, que le den ejemplo a sus.padres, esposos e hijos $^{\text {s4 }}$, incluso aparece en la Revista Portuense que se ha suprimido ala misa mayor en la iglesia Mayor Prioral para que puedan concurrir a los colegios electorales"ss.

(48) REVTSTA PORTUENSE. 15 de noviembre de 1933. .!Mujeres valientes!.

(49) REVISTA PORTJENSE. 9 de noviembre de 1933, .Otro peligro....

(50) REVISTA PORTUENSE. 15 de noviembre de 1933, s!Mujeres valientes!n.

(51) IBIDEM.

(52) REVISTA PORTUENSE. 9 de noviembre de 1933, .Otro peligro....

(53) REVISTA PORTUENSE. 8 de noviembre de 1933, ¿¿Sabeis....

(54) REVISTA PORTUENSE. 11 de noviembre de 1933, .Votad temprano.

(55) REVTSTA PORTUENSE. 16 de noviembre de 1933, •Apuntes y noticias. 
En todo este periodo las mujeres han asistido en gran número a los mítines organizados de uno u otro signo políticos6. En algunas ocasiones han participado como oradoras en los mítines: Luz Garcia en el Centro Obrero de la calle Pablo Iglesias, Micaela de Castro en un mitin del Partido Comunista, Carmen Alba Navas, como presidenta del comité femenino de la Juventud Tradicionalista, etc ${ }^{57}$.

También aparecen en la prensa artículos firmados por mujeres, como Isabel Expósito, en Trabajo!y Emilia Puente Buada, en la Revista Portuense ${ }^{88}$.

Igualmente, se ha podido constatar para estas elecciones la participación de mujeres en los trabajos de formación del Censo Electoral, como agentes auxiliares de la Junta Municipal del Censo. De un total de dieciseis nombres, dos eran mujeres ${ }^{59}$. En la constitución de las mesas electorales también había mujeres, aunque sólo como Adjuntos y Adjuntos Suplentes ${ }^{60}$.

El día de las elecciones (19-Nov-33), según la prensa, no se produjo ningún tipo de alteración ni incidentes y todo discurrió con normalidad. Días antes en el Bando del Gobernador Civil de la Provincia se hacía hincapié en que las mujeres iban a votar por vez primera y llamaba •a la cultura de todos para que en dicho día pongan especial cuidado en evitar, por el respeto debido a su sexo, alarmas y molestias que no sean las propias del ejercicio de tan cívica función. ${ }^{61}$.

Los testimonios personales recogidos también resaltan la tranquilidad de la jornada y la presencia de mujeres en las filas para votar en los colegios electorales ${ }^{62}$.

(56) En la REVTSTA PORTUENSE aparece en los días 7, 17 y 18 de noviembre de 1933 , referencias de ello. Asi mismo, según el testimonio oral de R.R., el 5 de febrero de 1933, eran muchas las mujeres que asistian a los actos de la izquierda.

(57) REVISTA PORTUENSE, 20 de noviembre de 1931, .Mitin en el Centro Obrero. A.M.E.P.S.M., -Mitin del Partido Comunista, el 6 de noviembre' de 1933 y •Acto de la Juventud Tradicionalista, el 25 de agosto de 1933. Los dos en el Leg. H-127.

(58) Tanto Luz Garcia como Isabel expósito eran conocidas socialistas, que actuaron como proselitistas y oradoras, por todo el territorio nacional. CALVO ORTEGA, ISABEL (et al.): La mujer en el mundo contemporáneo. Realidad y perspectiva. Málaga, Diputación Provincial, 1991.

(59) Se encontraban Dña. Margarita y Dña. Milagros Tendero Pérez. A.M.E.P.S.M., leg. H-548. Elecciones, 1931-36. 24 de Febrero de 1932. REVTSTA PORTUENSE, 25 de febrero de 1932.

(60) Como Adjuntos: Dña. Josefa López Bardallo, Dña. Milagros López y Dña. Juana López Rodríguez; y como Adjuntos Suplentes: Dña. Josefa Zapata Rodríguez y Dña., Ana Macías González. REVISTA PORTUENSE, 10 de noviembre de 1933.

(61) REVISTA PORTUENSE, 16 de noviembre de 1933. .Bando del Gobernador Civil de la Provincia de Cádiz.

(62) Testimonio oral de M.D.A., el 24 de enero de 1991. Testimonio oral de R.R., el 5 de febrero de 1991. Este último testimonio aportaba, además, algunas anécdotas, como la que ocurrió en una de las mesas electorales, en la que la derecha había sacado a las monjas de los dos conventos cercanos para así adjudicarse esos votos y la izquierda, por su parte; hizo lo mismo en una casa de prostitución. La reunión de mujeres tan dispares en la misma fila de votantes hizo que se produjeran algunos comentarios que se salieron de tono. 
El resultado electoral, como se sabe, supuso, a nivel general, el triunfo de las derechas en España, dando comienzo el llamado Bienio Radical-Cedista. Los partidos de izquierda culparon al voto femenino de la victoria de la derecha, y para ésta fue gracias al voto de las mujeres por lo que consiguieron el poder. Ambos le dieron demasiada importancia al voto femenino sin considerar otros factores: Los partidos de derechas formaban un frente común, y se habían fortalecidos en los últimos dos años, mientras que los de izquierdas, se encontraban desgastados y desacreditados por su actuación gubernamental. El gobierno republicano recibía ataques tanto de la derecha como de la izquierda. La reforma social y económica prometida no se había realizado. Se dieron numerosas huelgas, sucesos como el de "Casas Viejas", etc. Y, además, la desorganización de los partidos de izquierdas y la abstención propugnada por los anarquistas fueron claves para la decisión final del electorado.

En la provincia de Cádiz votaron el 37,27\% del Censo, llegando el porcentaje de abstención al $62,73 \%$, el más alto de toda España ${ }^{63}$.

El Puerto fue uno de los pocos pueblos de la provincia en que se alcanza el $65 \%$ de participación en las elecciones, superándole solamente El Bosque. El resto de las localidades gaditanas quedaron por debajo en cuanto al porcentaje de participación. Otra cuestión muy importante a tener en cuenta, es el propio resultado de la votación. Mientras que en la provincia de Cádiz y el resto de España ganaron las derechas, en EL Puerto fue la Candidatura Republicana de Izquierda la que obtuvo la mayoría en las elecciones ${ }^{64}$.

El número de electores en El Puerto era de 9.388. Acudieron a las urnas 6.136 , siendo el porcentaje de participación, concretamente del $64,59 \%{ }^{65}$.

Para analizar los resultados electorales nos centraremos en dos de los tres distritos utilizados anteriormente para estudiar la situación laboral y cultural de las mujeres portuenses, y que corresponden a los dos distritos de la Primera Circuscripción electoral.

El número de electores de los distritos 1 y 2 fue de 4.672 , siendo el de votantes 3.056. El porcentaje de participación ascendió al 65,41\%, mayor, aún, como puede observarse, que la media de la ciudad.

(63) CARO CANCELA, DIEGO: La Segunda República en Cádiz. Elecciones y Partidos Polúticos. Cádiz, Diputación Provincial, 1987. Pág. 191.

(64) En la provincia de Cádiz, El Puerto y La Línea fueron los dos pueblos donde se produjo la victoria de la Coalicción de Izquierdas. CARO CANCELA, DIEGO, op. cit., pág. 206.

(65) REVTSTA PORTUENSE. 21 de noviémbre de 1933. 
El tanto por ciento que obtuvieron los distintos grupos políticos en la Primera circuscripción, fue el siguiente ${ }^{66}$ :

$\begin{array}{lr}\text { Candidatura Republicana de Izquierdas } & 56,29 \% \\ \text { Frente de Derechas } & 32,29 \% \\ \text { Candidatura Radical } & 7,13 \% \\ \text { Frente Unico Revolucionario } & 4,17 \%\end{array}$

De todos estos resultados sería interesante conocer cuál fue la participación femenina en estas elecciones. Cuántos de esos 3.056 votantes eran mujeres. No existe hasta la fecha referencia alguna de las actas electorales donde se especifique el número exacto de mujeres y hombres que votaron. Sin embargo con los datos que contamos sípodemos llegar a conclusiones significativas con respecto a la participación de las mujeres portuenses.

Por una parte, se ha podido constatar, según el padrón, que de los electores, más del $52 \%$ lo constituían mujeres ${ }^{67}$, por lo que de 4.672 electores, se puede decir que al menos 2.429 eran mujeres y 2.243 hombres. Conociendo, pues, la cantidad de votantes (3.056), se puede afirmar que aún en el caso de que hubise votado el $100 \%$ de los hombres, el número de votos femeninos ya hubiera superado los 800 . Sin embargo, se pueden hacer aproximaciones más lógicas y reales. Para ello se cuenta con una referencia significativa: los datos de las elecciones de 1.931, en las que sólo votaron hombres. En ellas el porcentaje de participación fue del $62 \%$. En un primer supuesto, y considerando que se mantuviera ese mismo porcentaje de participación masculina, el nivel de participación femenina tendría que ser, por lo tanto, del $68 \%$ (ya que la media es del $65 \%$ ), lo que traducido a cifras sería: 1.419 hombres y 1637 mujeres.

En un segundo supuesto, estimando que la participación masculina se hubiese incrementado del $62 \%$ al $65 \%$, lógicamente la participación de mujeres y hombres sería equivalente, aunque las mujeres por constituir el $51 \%$ de los electores sería superior en número: 1.488 hombres y 1.568 mujeres.

En el tercer supuesto, considerando que el incremento de votantes masculinos llegase a alcanzar el $70 \%$, cosa poco probable, la participación femenina sería del $60 \%$, que en cifras reales constituiría una diferencia con respecto a los hombres del 4,8\%, es decir: 1.602 hombres y 1.454

(66) Elaboración propia a partir de los datos generales aportados por CARO CANCELA en La Segunda República, op: cit., pág. 196.

(67) Este porcentaje se ha obtenido a partir del Padrón de Habitantes de 1930, tomando como referencia la población de 18 y 21 años en adelante $(52,74 \%$ y $52,72 \%$ respectivamente). En España era del $51,84 \%$, según las cifras publicadas por el Instituto Nacional de Estadística en su •Anuario Estadístico Nacional. de 1934. 
mujeres. Como se puede observar, aún en el peor de los casos, habría 148 votos masculinos más que femeninos, una diferencia mínima.

Con todo, los supuestos parten de concederle a los hombres al menos el porcentaje de participación que ya poseían, es decir, que si se tuviera en cuenta la posibilidad de que la participación masculina hubiese disminuído, quizás por la influencia anarquista que propugnaba la abstención, la superioridad de las mujeres en la votación sería aún más palpable.

Por todo lo dicho anteriomente se podría concluir que las mujeres no se abstuvieron de votar en su mayoría, y que sus votos incidieron de forma decisiva en que la Coalicción de izquierda obtuviese la mayoría, al contrario del criterio sobre lo ocurrido a nivel nacional.

Habría que señalar que el comportamiento de las mujeres ante el voto no difería mucho del de los hombres. A nivel general, las mujeres cuyos maridos o familiares se inclinaban a la izquierda, votaban también por ello, y lo mismo ocurría en el caso de la derecha. De esta manera, la participación electoral de las mujeres fue similar a la de los hombres, y tanto en los casos donde se dio la victoria de la izquierda, como en la mayoritaria victoria conservadora, fueron debidos tanto al voto de los hombres como al de las mujeres ${ }^{68}$. Como afirmaba Clara Campoamor: «La mujer, en su actuación política, es movida por reacciones de tipo nacional, ni más ni menos que el varón, en los que olvida hasta sus intereses específicos; por lo que su intervención, al menos en sus primeros tiempos, no hará sino duplicar los votos; sin que sea causa de desvio hacia una política determinada ${ }^{69}$.

Tanto la derecha como la izquierda, con alabanzas y acusaciones, atribuyeron el triunfo conservador de las elecciones de 1933, al comportamiento electoral de las mujeres. En la REVISTA PORTUENSE se decía:

:Terminada la contienda en que la mujer ha desempeñado un papel imteresantísimo y ha dado pruebas de ejemplar abnegación cívica, démonos por muy satisfechos por su resultado ${ }^{70}$.

En cambio en TRABAJO! aparecía una muy diferente interpretación:

(68) VILANOVA, MERCEDES: ‘La elección legislativa del 19 de noviembre de 1933 en Cataluña y la tergiversación historiógráfica del voto de la mujer. en Haciendo bistoria: Homenaje al Prof. Carlos Seco. Madrid, Universidad Complutense, 1989. Pág. 533. GARCIA JORDAN, PILAR: .Voto femenino. Repercusiones de su concesión y canalización del mismo por los sectores conservadores catalanes, 1931-1936., en Ordenamiento jurídico y realidad sacial de las mujeres. Actas de las IV Jornadas de Investigación Interdisciplinaria sobre la Mujer. Madrid, Universidad Autónoma, 1986.

(69) CAMPOAMOR, CLARA: Mi pecado mortal. El voto femenino y yo. Introducción de C. Fagoaga y P. Saavedra. Barcelona, 1981. Pág. 251.

(70) REVISTA PORTUENSE. 23 de noviembre de 1933. 
* concerderle el voto a la mujer ha sido tan insensato como entregarle a un niño un arma de fuego. ${ }^{71}$.

Una vez más se pone de manifiesto la manipulación histórica de que fueron objeto las mujeres.

En las elecciones del 16 de Febrero de 1936 es el Frente Popular quien se alza con la victoria y también se hizo responsable de ello' a las mujeres, sin tener en cuenta que el panorama electoral español se mostraba muy diferente. La tensión socio-política era muy superior a la registrada dos años antes, existiendo un fuerte enfrentamiento entre los extremos políticos de derechas e izquierdas. La izquierda se presentaba a las elecciones formando el Frente Popular. Habían recuperado el prestigio y los anarquistas no se íban a abstener en la votación. Por otra parte, el gobierno radical-cedista defraudólas esperanzas depositadas en él por la clase media y, en general, por gran parte de los españoles. En El Puerto las condiciones de las mujeres ante las elecciones de 1936, eran diferentes a las del anterior comicio. Existía una mayor participación política, muchas mujeres se encontraban organizadas en las Juventudes Marxistas, en el Socorro Rojo, formando un grupo de mujeres en la Casa del Pueblo... así como, también, organizadas en grupos políticos de derechas (Acción Ciudadana, Juventud Femenina, Juventudes Tradicionalistas, : Acción Católica, ,...). Había una mayor asistencia de mujeres a los actos públicos: mítines, manifestaciones, charlas, reuniones, etc. ${ }^{72}$.

En cuanto a la campaña electoral, en el periódico TRABAJO! la propaganda dirigida a la mujer es más numerosa que en la REVISTA PORTUENSE. Desde sus páginas, la izquierda pretende llegar a la mujer apelando a su sensibilidad, su compasión, siendo la anmistía y la represión los temas en los que más concienciadas se van a encontrar las mujeres. Otra de las cuestiones en siguen basando la propaganda es el tema de los hijos, marido y familia.

La derecha, sin embargo, va a mantener el mismo discurso de las elecciones del 33 (Religión, Patria y Hogar) e insiste en que las mujeres deben repetir lo que ya hicieron en las pasadas elecciones, manteniendo además de su propaganda, otros actos indirectos como: donativos, repartos de alimentos, premios, etc $\mathrm{c}^{73}$.

No se pretende profundizar en las elecciones de 1936, ya que su extensión excedería en mucho este artículo. La victoria del Frente Popular

(71) TRABAJO!, 14 de septiembre de 1935.

(72) Referencias de ello, se encuentran en TRABAJO!: 26 de octubre de 1935, 18 y 25 de enero y 8 de febrero de 1936. También en la REVISTA PORTUENSE: 4 y 15 de febrero de 1936. En este último mitin estuvo como oradora la portuense Dña Emilia Puente Buada.

(73) REVISTA PORTUENSE, 21 y 25 de enero de 1936. 
tuvo poca duración, el 18 de julio de ese mismo año el golpe de estado de Franco, acabó con sus espectativas y las de la II República. De esta forma acababa un periodo, que tuvo su importancia para las mujeres. Además de la concesión del voto femenino, se dióuna importante labor legislativa, de cara a la mujer, en el ámbito familiar y laboral, un gran impulso educativo, etc. Por otra parte, la vida política adquiere en esta época una intensidad singular. Las mujeres van a participar, en su medida, de esta intensidad, comenzando a introducirse en los partidos políticos, e incluso formando asociaciones y grupos feministas de carácter político.

Todo esto será determinante para que sea en este período cuando comiencen a darse, aunque lentamente, las primeras fisuras en la rígida distribución de papeles sociales.

Las mujeres, como muchos sectores de la población, esperaban de la II República importantes cambios en sus múltiples problemas de desigualdad: política, social, trabajo, educación, etc. Sin embargo, la corta duración de este período, hizo que no cuajasen los cambios producidos en la sociedad.

Se podría decir que la República constituyó un inicio importante en la lucha por la igualdad, aunque ésta quedó paralizada, incluso retrocediendo en muchos aspectos, con la dictadura. Desde los inicios de este periodo franquista se pretende mantener a las mujeres en el ámbito doméstico, cerrándoles las puertas de la política, el trabajo, la educación profesional ... Como nos decía Clara Campoamor desde su exilio en Suiza en 1959: “Cuando veo cuál ha sido el resultado de nuestras luchas y esfuerzos me pregunto si verdaderamente vale la pena hacer algo en la vida ... cierto que no hay otro país como el nuestro para el paso atrás y la vuelta al medioevo. Creo que lo único que ha quedado de la Reública fue lo que yo hice: el voto femenino, pues aunque resulte la igualdad en la nada, no se han decidido a borrarlo, ...74 .

(74) FAGOAGA, CONCHA y SAAVEDRA, PALOMA, Introducción al libro de CAMPOAMOR, CLARA: Mi pecado mortal. El voto femenino y yo. Pág. XXIII. 